American Journal of Applied Sciences 6 (8): 1495-1501, 2009

ISSN 1546-9239

(C) 2009 Science Publications

\title{
Thermal Comfort Assessment: A Case Study at Malaysian Automotive Industry
}

\author{
${ }^{1}$ A.R. Ismail, ${ }^{2}$ N. Jusoh, ${ }^{1}$ R. Zulkifli, ${ }^{2}$ K. Sopian and ${ }^{1}$ B.M. Deros \\ ${ }^{1}$ Department of Mechanical and Materials Engineering, Faculty of Engineering and Built Environment, \\ University Kebangsaan Malaysia, 43600 UKM Bangi, Malaysia \\ ${ }^{2}$ Solar Energy Research Institute, University Kebangsaan Malaysia, 43600 UKM Bangi, Malaysia
}

\begin{abstract}
Problem statement: Thermal comfort has a great influence on the productivity and satisfaction of indoor building occupants. The exposure to excessive heat during work may cause discomfort and contributed to low productivity among workers. Malaysia known with its hot and humid weather where in most of the survey study published indicated that workers in Malaysia automotive industries had exposed to excessive temperature while working. The study investigated the thermal comfort level experienced by workers at Malaysian automotive industry. Approach: The study had been conducted at one automotive parts assembly factory in Malaysia. The human subjects for the study constitute operators at tire receiving section of the factory. The environment examined was the relative humidity $(\%)$, WBGT, air temperature and radiant temperature $\left({ }^{\circ} \mathrm{C}\right)$ of the surrounding workstation area. The environmental factors were measured using Babuc apparatus, which is capable to measure simultaneously those mentioned environmental factors. The time series data of fluctuating level of factors were plotted to identify the significant changes of factors. Then thermal comfort of the workers was assessed by using ASHRAE thermal sensation scale by using Predicted Mean Vote (PMV). Further Predicted Percentage Dissatisfied (PPD) was used to estimate the thermal comfort satisfaction of the occupant. Finally the PPD versus PMV were plotted to present the thermal comfort scenario of workers involved in related workstation. Results: The trend of relative humidity curve from the graph also indicated the increasing level of discomfort. The radiant temperature observed seems consistent during the study while there was decreasing of WBGT start from afternoon due to the rain. The study revealed that the PPD value of $54 \%$ of the workers population at the workstation are likely to be satisfied with thermal comfort at this station while the PMV index from ASHRAE indicated the value 1.07-1.41. Conclusion: The empirical study from the PPD and PMV index indicated that workers working at this were influenced by the heat. The less of PPD value from $80 \%$ of the population satisfied with the thermal comfort showed the environment factors that were not good for worker while the PMV index showed the area of work is slightly warm.
\end{abstract}

Key words: Thermal comfort, temperature, predicted percentage dissatisfied, predicted mean vote

\section{INTRODUCTION}

Thermal comfort has a great influence on the productivity and satisfaction of indoor building occupants $^{[13]}$. Thermal comfort is very difficult to define. This is because we need to take into account a range of environmental and personal factors when deciding on the temperatures and ventilation that will make feel comfortable. The best that we can realistically hope to achieve is a thermal environment which satisfies the majority of people in the workplace, or put more simply, 'reasonable comfort ${ }^{[10]}$.

Thermal comfort can be defined as that condition of mind which expresses satisfaction with the thermal environment ${ }^{[1]}$. The reference to 'mind' indicates that it is essentially a subjective term; however, there has been extensive research in this area and a number of indices exist which can be used to assess environments for thermal comfort ${ }^{[12]}$. Fanger ${ }^{[5]}$ suggested three conditions for comfort; these are that the body is in heat balance and that the mean skin temperature and sweat rate are within limits required for comfort. Conditions required for heat balance can be derived from a heat balance equation. Mean skin temperatures and sweat rates that are acceptable for comfort have been derived from empirical investigation ${ }^{[5]}$.

Corresponding Author: A.R. Ismail, Department of Mechanical and Materials Engineering, Faculty of Engineering and Built Environment, University Kebangsaan Malaysia, 43600 UKM Bangi, Malaysia 


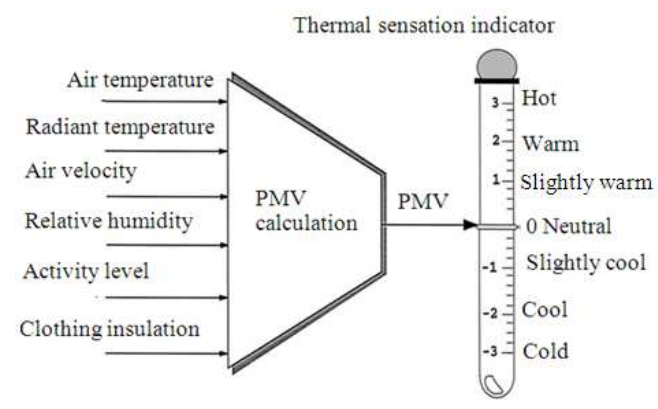

Fig 1: PMV and thermal sensation

Predicted Mean Vote (PMV) is a parameter for assessing thermal comfort in an occupied zone based on the conditions of metabolic rate, clothing, air speed besides temperature and humidity. PMV values refer the ASHRAE thermal sensation scale ${ }^{[1]}$ that ranges from-3 as follows: $3=$ hot, $2=$ warm, $1=$ slightly warm, $\quad 0=$ neutral,$\quad-1=$ slightly cool, $-2=$ cool, $-3=$ cold. Figure 1 shows the overall process of using the six variables associated with thermal comfort sensation to evaluate the $\mathrm{PMV}^{[8]}$. The general comfort equation developed by Fanger $^{[5]}$ to describe the conditions under which a large group of people will feel in thermal neutrality is too complex and cannot be used in real time applications.

Equation 1-3 shows the comfort equation proposed by Fanger ${ }^{[13]}$ :

$$
\begin{aligned}
\text { PMV }= & \left(0.028+0.3033 \mathrm{e}^{-0.036 \mathrm{M}}\right)\{(\mathrm{M}-\mathrm{W})-3.05 \\
& {[5.733-0.000699(\mathrm{M}-\mathrm{W})-\mathrm{Pa}] } \\
& -0.42[(\mathrm{M}-\mathrm{W})-58.15]-0.0173 \\
& \mathrm{M}(5.867-\mathrm{Pa})-0.0014 \mathrm{M}\left(34-\mathrm{T}_{\mathrm{a}}\right) \\
& -3.96 \times 10^{-8} \mathrm{fcl}\left[\left(\mathrm{T}_{\mathrm{cl}}+273\right)^{4}-\left(\mathrm{T}_{\mathrm{mrt}}+273\right)^{4}\right] \\
& \left.- \text { fcl.hc }\left(\mathrm{T}_{\mathrm{cl}}-\mathrm{T}_{\mathrm{a}}\right)\right\}
\end{aligned}
$$

Where:

$$
\begin{aligned}
\mathrm{T}_{\mathrm{cl}}= & 35.7-0.028(\mathrm{M}-\mathrm{W})-0.155 \mathrm{I}_{\mathrm{cl}}\left[3.96 \times 10^{-3} \mathrm{fcl}\left[\left(\mathrm{T}_{\mathrm{cl}}+273\right)^{4}\right.\right. \\
& \left.-\left(\mathrm{T}_{\mathrm{mrt}}+273\right)^{4}\right]-\mathrm{fcl} . \mathrm{hc}\left(\mathrm{T}_{\mathrm{cl}}-\mathrm{T}_{\mathrm{a}}\right) \\
\mathrm{h}_{\mathrm{c}}= & \left\{\begin{array}{l}
2.38\left(\mathrm{~T}_{\mathrm{cl}}-\mathrm{T}_{\mathrm{a}}\right)^{0.25} \\
\left.12.1 \sqrt{\mathrm{V}_{\text {air }}} \mathrm{for}^{\mathrm{for} 2.38} 2.38\left(\mathrm{~T}_{\mathrm{cl}}+\mathrm{T}_{\mathrm{cl}}-\mathrm{T}_{\mathrm{a}}\right)^{0.25}\right)^{0.25} \leq 12.1 \sqrt{\mathrm{V}_{\text {air }}}
\end{array}\right.
\end{aligned}
$$

The parameters are defined as follows:

$$
\begin{aligned}
\mathrm{PMV}= & \text { Predicted mean vote } \\
\mathrm{M}= & \text { Metabolism }\left(\mathrm{W} \mathrm{m}^{-2}\right) \\
\mathrm{W}= & \text { External work, equal to zero for most activity } \\
& \left(\mathrm{W} \mathrm{m}^{-2}\right)
\end{aligned}
$$

$\mathrm{I}_{\mathrm{cl}} \quad=$ Thermal resistance of clothing (Clo)

$\mathrm{f}_{\mathrm{cl}}=$ Ratio of body's surface area when fully clothed to body's surface area when nude

$\mathrm{T}_{\mathrm{a}}=$ Air temperature $\left({ }^{\circ} \mathrm{C}\right)$

$\mathrm{T}_{\text {mrt }}=$ Mean radiant temperature $\left({ }^{\circ} \mathrm{C}\right)$

$\mathrm{V}_{\text {air }}=$ Relative air velocity $\left(\mathrm{m} \mathrm{sec}^{-1}\right)$

$\mathrm{Pa}=$ Partial water vapor pressure $(\mathrm{Pa})$

$\mathrm{h}_{\mathrm{c}} \quad=$ Convectional heat transfer coefficient $\left(\mathrm{W} \mathrm{m} \mathrm{m}^{-2} \mathrm{~K}\right.$ )

$\mathrm{T}_{\mathrm{cl}}=$ Surface temperature of clothing $\left({ }^{\circ} \mathrm{C}\right)$

Furthermore, the equation for PPD is given by Eq. 4:

$\mathrm{PPD}=100-95 \exp \left(-0.03353 \mathrm{PMV}^{4}+0.2179 \mathrm{PMV}^{2}\right)$

Predicted Percentage Dissatisfied (PPD) is used to estimate the thermal comfort satisfaction of the occupant. It is considered that satisfying 80 of occupant is good: That is, PPD less than $20 \%$ is good ${ }^{[8]}$.

Malaysia has one of the fastest growing building industries worldwide, where the corresponding energy demand would significantly increase in the next coming years. The energy demand scenario in buildings can be understood from the experience of developed nation. Malaysia which is on the track towards a developed nation must understand and proactively be prepared for the potential implication. Considering the average temperature for typical towns in Malaysia, it seems that air conditioning during office hours is a must if people living in the hot and humid climate like Malaysia want a thermal comfort in the building space during the day. Nevertheless, wherever possible if air conditioning can be avoided in the residential houses, without compromising thermal comfort that possibility must be explored.

Most of the developing nation like Malaysia intends to develop in a sustainable manner. Sustainable development is defined as the development that meets the needs of the present without compromising the ability of future generations to meet their own needs.

Without ventilation, a building's occupants will first be troubled by ad ours and other possible contaminants and heat ${ }^{[17]}$. When we discuss about heat, actually automatically discuss about thermal comfort building's occupant. In most cases, buildings are erected to protect their occupants from the external environment (e.g., extreme temperatures, wind, rain and radiation) and to provide them with a good indoor environment. Proton Factory is using natural ventilation. This ventilation is different with mechanical ventilation. Three objectives of natural ventilation are indoor air quality, thermal comfort and energy savings ${ }^{[17]}$. 
The good building design characteristic, including both the engineering and non engineering disciplines, might be summarized as follow ${ }^{[7]}$ :

- Meets the purpose and needs of the building's owners/managers and occupants

- Meets the requirements of health, safety and environmental impact as prescribed by codes and recommend by consensus standards

- Achieves good indoor environment quality which in turn encompasses high quality in the following dimensions: Thermal comfort, indoor air quality, acoustical comfort, visual comfort

- Creates the intended emotional impact on the building's occupants and beholders

Improving workers' productivity, occupational health and safety are major concerns of industry, especially in developing countries. However, these industries are featured with improper workplace design, ill-structured jobs, mismatch between workers' abilities and job demands, adverse environment, poor humanmachine system design and inappropriate management programs ${ }^{[16]}$. Light, noise, air quality and the thermal environment were considered factors that would influence the acceptability and performance on the occupants of premises ${ }^{[3,11]}$ stated that lower emotional health is manifested as psychological distress, depression and anxiety, whereas lower physical health is manifested as heart disease, insomnia, headaches and infections. These health problems could lead to organizational symptoms such as job dissatisfaction, absenteeism and poor work quality. Irritated, sore eyes and throat, hoarseness, stuffy congested nose, excessive mental fatigue, headache and unusual tiredness were all signs of the negative workplace environmental conditions $^{[18]}$.

Previous research done by ${ }^{[4]}$ showed that the work environments were associated with perceived effects of work on health. This research used a national sample of 2048 workers who were asked to rate the impact of their respective jobs job on their physical and mental health. Regression analyses proved that the workers' responses were significantly correlated with health outcomes. In addition to this, Shikdar et al. ${ }^{[16]}$ pointed out that there was high correlation between performance indicators and health, facilities and environmental attributes ${ }^{[11]}$. In other words, companies with higher health, facilities and environmental problems could face more performance related problems such as low productivity and high absenteeism. Employees with complaints of discomfort and dissatisfaction at work could have their productivity affected, result of their inability to perform their work properly ${ }^{[9]}$.

Increased attention had focused on the relationship between the work environment and productivity since the 1990s. Laboratory and field studies showed that the physical and chemical factors in the work environment could have a notable impact on the health and performance of the occupants and consequently on the productivity. Workplace environmental conditions, such as humidity, indoor air quality and acoustics have significant relationships with workers' satisfaction and performance ${ }^{[2,4,6]}$. Indoors air quality could have a direct impact on health problems and leads to uncomfortable workplace environments ${ }^{[14,15,19]}$.

\section{MATERIALS AND METHODS}

Description of tire receiving workstation: The station measurements took place was the Tire-receiving station. It is located not directly at the assembly belt. The location is very close to the loading ramps at the site of the plant. It mainly consists of a conveyer belt, approximately 10 meters long and a row of containers, filled with new tires, which can be seen in Fig. 2. Both, conveyer and container are divided by a narrow path for the operator. He is picking constantly new tires from the container and puts them onto the conveyer belt. During this operation he was checking the tire for any damage and being filled with air. For the actual car produced, three different types of tires are available. Two different steel rims and one aluminum rim. A set of cards in the right order tells the worker, which type of wheel needs to be put on the belt next. Each card is valid for five tires, four plus one spare wheel. Each card is attached to the first tire of each set to document it at the tire mounting station. As spare wheel always steel rims are used, even with sets of aluminum rims. The conveyer belt is operated manually. It is consisting of rollers, on which the tires can be pushed easily. At the one end of the conveyer, the tires are transferred to an automatic conveyer belt. It transports the tires to an elevator, to transfer them about 4 meters high above a small road inside the plant to the assembly line. During this transfer the tires are divided into sets of two and three, for the left and right side of the car. The whole station in operated by two workers. One worker is putting the tires on the conveyer, while the other one is driving a forklift truck, to exchange the empty containers with new ones. Figure 3 exemplifies the standard of procedure involve in completing task at tire receiving workstation. 


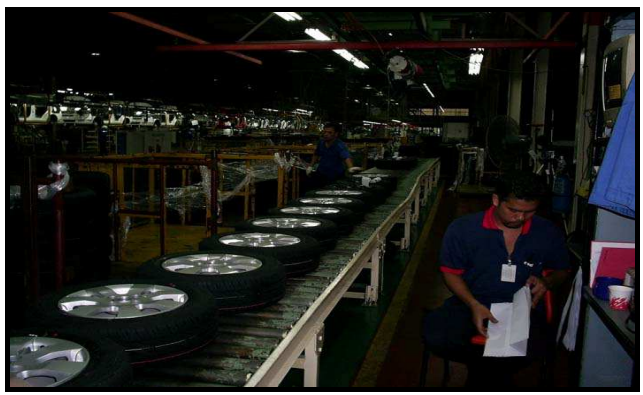

Fig 2: Tire receiving station

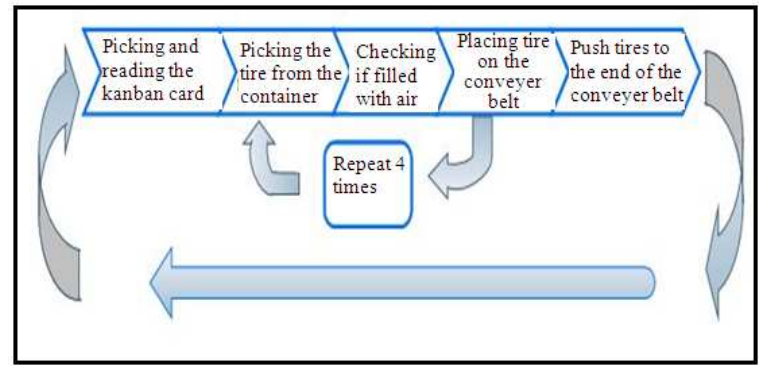

Fig. 3: Workflow at the tire receiving workstation

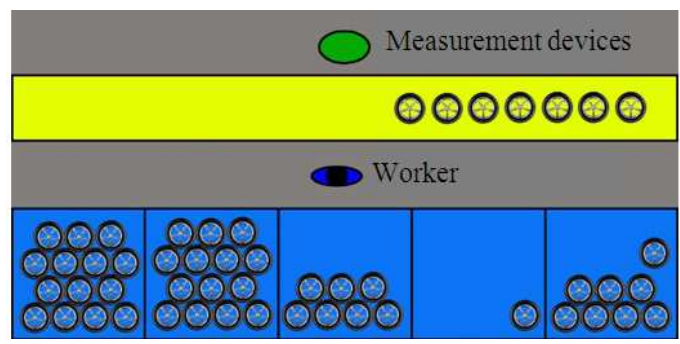

Fig. 4: Position of the measurement device

The measurement equipment was set up at the opposite site to the worker at the conveyer belt, shown in Fig. 4. The power supply could be arranged completely on this side of the conveyer, disturbing neither the operator nor the other workers passing by on forklift trucks. In approximately $3 \mathrm{~m}$ height strip lights were mounted to both sides of the conveyer belt. At the belt also 4 large fans were mounted and two separate fans at the rest area. The position of the measurement devices was equivalent to the worker. The temperature was cooled down by the fans at both sides of the conveyer belt. Hence the temperature should be the same at each side of the conveyer belt. The same conditions are valid for the Humidity. The position of the psychrometer should have produce equivalent values, as on the operator's side. The conditions of illuminance were, due to the arrangement of the strip lights at both sides of the conveyer belt equivalent too.

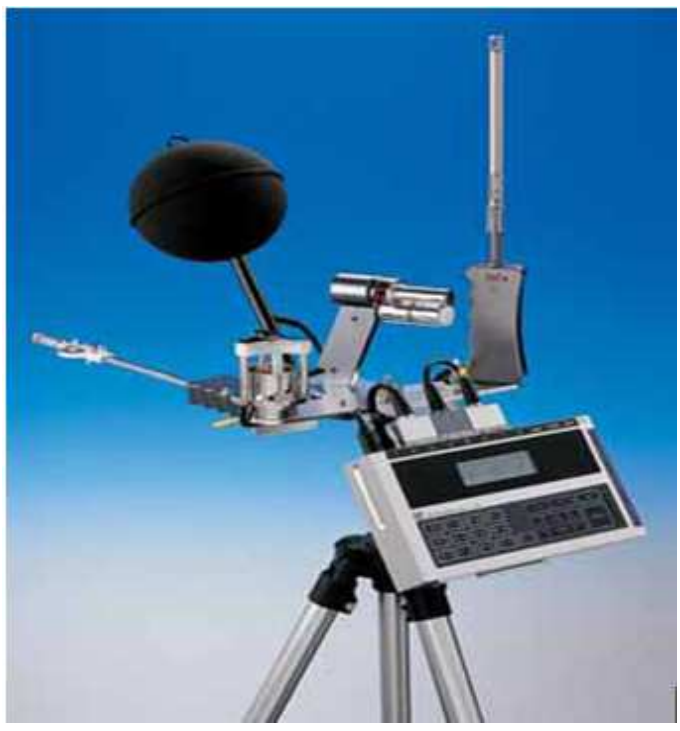

Fig. 5: Complete integrated Babuc A Apparatus

The lux meter was placed on the tripod for all sensors, open to all sides.

The measurements started at 9:20 am. Due to the delay of some of the participants the starting in time was not possible. Hence the safety instruction had to be rescheduled to $8: 45 \mathrm{am}$. The equipment was put up as fast as possible, but to take care of it, at least $15 \mathrm{~min}$. were needed. Once started, the remaining day, the measurement of the productivity was accomplished. In steps of ten minutes, the amount of tires placed on the conveyer belt was counted and written down for further analysis. The workers finished their work at 5:20 pm. With this time the measurements were stopped too.

Equipments: The basic device for the measurements was the Babuc A multi-data inquisition unit as a shown in Fig. 5. This instrument was used to obtain value air temperature, air humidity, mean radiant temperature, relative air velocity, activity level (heat production in the body), thermal resistance of the clothing (clo-value).

\section{RESULTS}

Time series analysis: The day started warm, but cloudy. When the measurements began, the temperature head already reached values of $26^{\circ} \mathrm{C}$. This is nothing special for a cloudy day in a region with tropical climate. During the day the temperature climbed up more or less constantly to almost $28^{\circ} \mathrm{C}$ at $1: 20 \mathrm{pm}$. Although the station was ventilated with large fans, the temperature could raise to this value. During afternoon the cloudiness gained and the temperature was going down significant, clearly to see in the graph. At 
2:15 pm it finally started to rain. The rain was quite heavy and lasted for about $45 \mathrm{~min}$. The work at this station was not disturbed in particular by the rain. During this time the temperatures stayed almost constant at a level of $25^{\circ} \mathrm{C}$. At 3:00 pm the rain stopped and the weather changed back to cloudy but dry. With the same increase, comparable to the raising in the beginning of the day, the temperatures climbed again up to highs of $27^{\circ} \mathrm{C}$ which is shows in Fig. 6. Between the start of the measurement and the time, the rain started, the humidity was slightly decreasing as shows in Fig. 7. With values of about $75 \%$ in the morning hours it got the lowest value of $63 \%$ at $12: 50 \mathrm{pm}$. When the amount of clouds started to increase, the humidity raised. Within $20 \mathrm{~min}$. it increased from about 70-90\%. With the start of rain it got its maximum of $92 \%$ and kept this range until the rain stopped. Then it decreased slowly to values around $70 \%$.

As we can see at Fig. 8 air temperature, the temperature increase constantly to almost the higher temperature is $31^{\circ} \mathrm{C}$ until $1.30 \mathrm{pm}$ and decrease after that. This is because at $2.15 \mathrm{pm}$ it started to rain. After $45 \mathrm{~min}$ raining stopped and the temperature increase constantly again. Figure 9 showed the radiant temperature at tyre receiving.

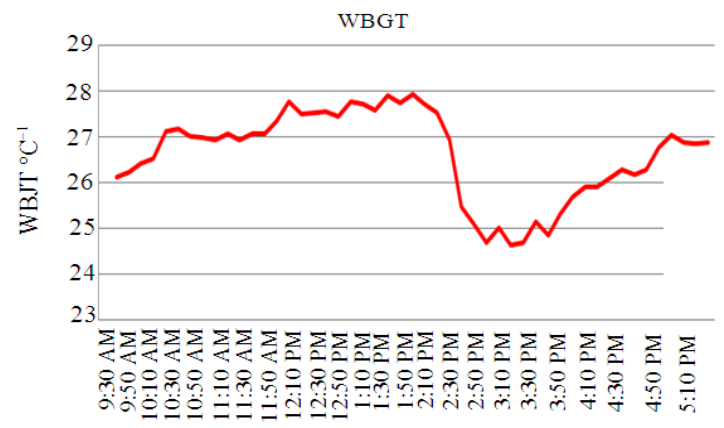

Fig. 6: WBGT measured at the tire receiving station

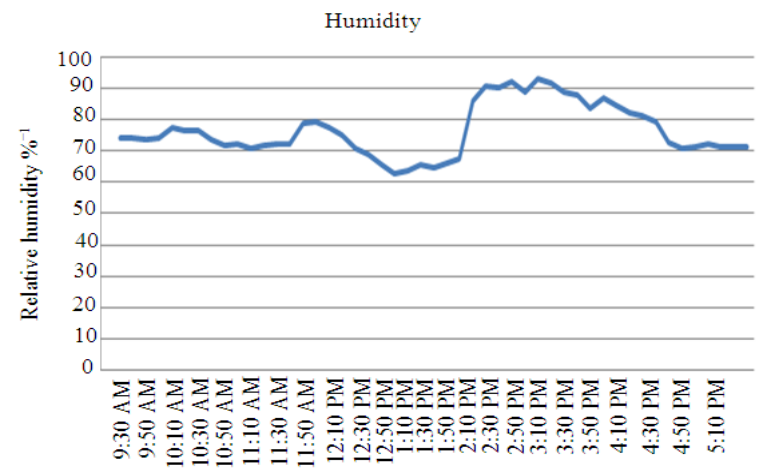

Fig. 7: Relative humidity measured at the tire receiving station
This curve in Fig. 4 is opposite with the air temperature in Fig. 2. The radiant temperature increase after heavy raining at $2.15 \mathrm{pm}$ which is the temperature the higher is $20^{\circ} \mathrm{C}$.

Due to its location close to the loading ramps very much influenced by the environment. This is because this station is very close to main door and windows as shown in Fig. 2 and 4. This door and windows is always open during work running.

Thermal comfort assessment: Structure of the paper would be the thermal comfort are examined, with six primary factors to most affect the thermal comfort are air temperature, humidity, air velocity, mean radiant temperature, clothing level and metabolic rate ${ }^{[8]}$.

Fig. 10 exemplified a summary of the PMV and PPD as one of thermal comfort index at tyre receiving station. It measure from heat loss by radiation from the person.

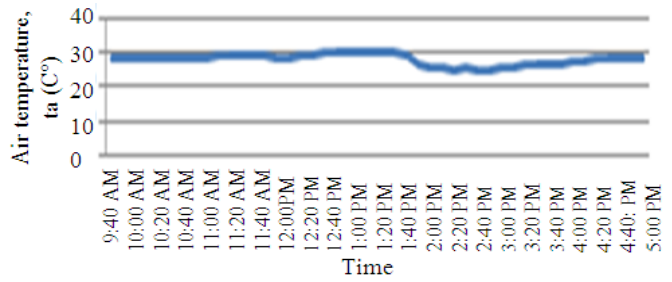

Fig. 8: Air temperature measured at the tire receiving station

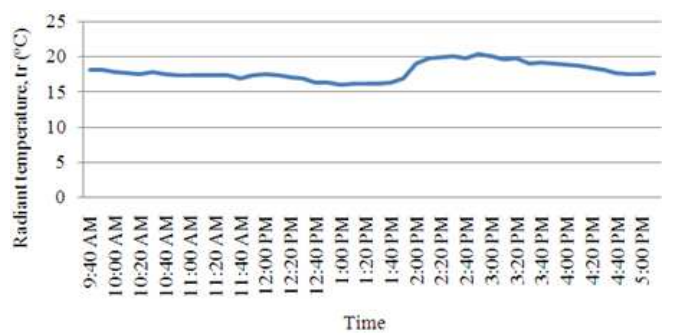

Fig. 9: Radiant temperature measured at the tire receiving station

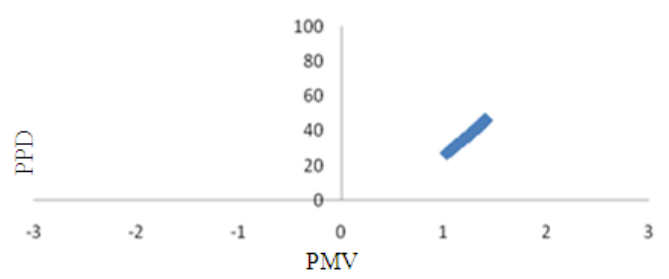

Fig. 10: PPD as a function for PMV at tire receiving Station 
Am. J. Applied Sci., 6 (8): 1495-1501, 2009

\section{DISCUSSION}

The influence of the rain to the temperature is very large. The metabolic rate calculated was $116 \mathrm{~W} \mathrm{~m}^{-2}$. The value according the clothes used was 0.8 Clo for short sleeves and light working trousers. The activity was moderate, rated with 1.995 met. This results in a reference temperature of $30^{\circ} \mathrm{C}$. The highest temperature measured was close to $28^{\circ} \mathrm{C}$. The measured temperature is acceptable.

The humidity, which is due to the tropical climate always very high, climbed to values above $90 \%$ when it rained. When the relative humidity reaches $100 \%$ the surrounding air is not capable of taking on much more water. The more heavier the raining, the higher relative humidity level. Radiant temperature was also influenced by air temperature. Clothing strongly modifies the comfort feeling in natural ventilation: the perception of heat is reduced consequently to the sweat evaporation on both skin and fabric. In this study the management of factory had been advised to suggest a relevant clothing index for their worker to wear in order to avoid excessive sweating among the workers.

Cooling the skin by sweating is under these conditions very difficult. The large fans are very important for the workers to ensure the heat exchange from their bodies to the surrounding air by heat convection. The heat exchange by evaporation would be poor with a relative humidity of $90 \%$ and above. The measured values at this station were very high. The recommended relative humidity of $50-60 \%$ is much overridden. The conditions were for sure uncomfortable for the workers

Predicted Mean Vote (PMV) is one way to quantify the comfort achieved in a space. PPD diagrams clearly show a high ratio of dissatisfied people. In respect of subjective thermal votes the workstation under survey are inappropriate. The scale for sensation vote towards thermal comfort is shown in Table 1. The thermal comfort of a factory worker depends on there being an average skin temperature (resulting from the combination of climate, clothing and metabolic heat production).

The thermal comfort assessment which shows from the PMV index and PPD was not in the comfort zone due to the PMV index is around 1.07-1.41. The PPD value were also low stated from $27-46 \%$. That's means the higher PPD in this station is 46 , so, the $54 \%$ are likely to be satisfied. The metabolic rate calculated was $116 \mathrm{~W} \mathrm{~m}^{-2}$. The value according the clothes used was 0.8 clo for short sleeves and light working trousers. The activity was moderate, rated with 1.995 met.
Table 1: Scale for sensation vote towards thermal comfort ${ }^{[27]}$

\begin{tabular}{llll}
\hline & Air temperature & Relative humidity & Air velocity \\
\hline-3 & Cold & Very humid & Very strong \\
-2 & Cool & Humid & Strong \\
-1 & Slightly cool & Slightly humid & Slightly strong \\
0 & Neutral & Neutral & Neutral \\
1 & Slightly warm & Slightly dry & Slightly weak \\
2 & Warm & Dry & Weak \\
3 & Hot & Very dry & Very weak \\
\hline
\end{tabular}

\section{CONCLUSION}

From the results we can conclude that there exist, the strong interdependence among environmental comfort factors. Furthermore the previous survey study results that had been conducted prior than this study showed the in line finding from the PPD and PMV index. Also the influences of the outdoor environment on the built environment were analyzed. The PMV at tyre receiving station is slightly warm. $54 \%$ are likely to be satisfied with thermal comfort at this station. The relationship between the relative humidity and WBGT were also obtained whereas during raining started the relative humidity of the environment will raise up. The findings were also in-line with the theory of relative humidity that is ratio of the partial pressure of water vapor in the mixture to the saturated vapor pressure of water at a prescribed temperature.

\section{REFERENCES}

1. ASHRAE Handbook, 2005. Fundamentals, American Society of Heating, Refrigerating AirCondition. Engineers. Inc., Atlanta. ISBN: 1931862710.

2. Czubaj, C.A., 2002. School indoor air quality. J. Instruct. $\quad$ Psychol., 29: 317-321. https://www4.infotrieve.com/neworders/Order_Cart.asp

3. Dua, J.K., 1994. Job stressors and their effects on physical health, emotional health and job satisfaction in a university. J. Educ. Administrat., 32: 59-78. DOI: $10.1108 / 09578239410051853$

4. Ettner, S.L. and J.G. Grzywacz, 2001. Workers perceptions of how jobs affect health: A social ecological perspective. J. Occup. Health Psychol., 6: 101-131. http://www.ncbi.nlm.nih.gov/pubmed/11326723

5. Fanger, P.O., 1970. Thermal Comfort. Danish Technical Press, Copenhagen, ISBN: 0-07-0199159, pp: 21-23

6. Fisk, W.J., 2000. Health and productivity gains from better indoor environments and their relationship with building energy efficiency. Ann. Rev. Energ. Environ., 25: 537-566. DOI: 10.1146/annurev.energy.25.1.537 
7. Ghiaus, C. and F. Allard, 2005. Natural Ventilation in the Urban Environment: Assessment and Design. Earthhscan, London, ISBN: 1844071294, pp: 256.

8. Hamdi, M., G. Lachiver and F. Michand, 1999. A new predictive thermal sensation index of human response. Energ. Build., 29: 167-178. http://cat.inist.fr/?aModele $=$ afficheN\&cpsidt $=1685$ 064

9. Leaman, A., 1995. Dissatisfaction and office productivity. Facilities, 13: 13-19. DOI: 10.1108/02632779510078102

10. Michael, J., 1999. Thermal Comfort in the Workplace: Guidance for Employers. Health Safe. Executive Books, ISBN: 0717624684, pp: 12 http://www.kent.ac.uk/safety/HSEguidetothermalc omfort.pdf

11. Olesen, B.W., 1995. International standards and the ergonomics of the thermal environment. J. Applied Ergonomics, 26: 293-302. DOI: 10.1016/00036870(95)00033-9

12. Parsons, K.C., 2000. Environmental ergonomics: A review of principles, methods and models. Applied Ergonom. 31: 581-594. http://cat.inist.fr/?aModele $=$ afficheN\&cpsidt $=8366$ 86

13. Roberto, Z.F., G.H.C. Oliveira and N. Mendes, 2008. Predictive controllers for thermal comfort optimization and energy savings. Energ. Build., 40: 1353-1365. DOI: 10.1016/j.enbuild.2007.12.007
14. Shek, K.W., W.T. Chan, 2008. Combined comfort model of thermal comfort and air quality on buses in Hong Kong. Sci. Total Environ., 389: 277-282. http://www.ncbi.nlm.nih.gov/pubmed/17949792

15. Shiaw-Fen Ferng, L.W.L., 2002. Indoor air quality assesment of day-care facilities with carbon dioxide, temperature and humidity as indicator. J. Environ. Health, 65: 14-18. http://www.ncbi.nlm.nih.gov/pubmed/12415886

16. Shikdar, A.A. and N.M. Sawaqed, 2003. Worker productivity and occupational health and safety issues in selected industries. Comput. Indus. Eng., 45: 563-572. http://portal.acm.org/citation.cfm?id=989503

17. Son, H., H.L. Rosario and M.M. Rahman, 2008. Thermal comfort enhancement by using a ceiling fan. Applied Therm. Eng., 29: 1648-1656. DOI: 10.1016/j.applthermaleng.2008.07.015

18. Tarcan, E., E.S. Varol and M. Ates, 2004. A qualitative study of facilities and their environmental performance management of environmental quality. Int. J., 15: 154-173. DOI: $10.1108 / 14777830410523099$

19. Wilson, S., 2001. Graduating to better IAQ. Consult. Specify. Eng., 29: 24-28. http://www.eric.ed.gov/ERICWebPortal/custom/po rtlets/recordDetails/detailmini.jsp?_n 